\title{
LABORATORY CHARACTERIZATION \\ OF THE LOAD TRANSFER-CRACK WIDTH \\ RELATION FOR INNOVATIVE SHORT \\ CONCRETE SLABS PAVEMENTS
}

\author{
MAURICIO PRADENA ${ }^{1 *}$, LAMBERT HOUBEN ${ }^{2}$, \\ ANDRÉS CÉSAR ${ }^{3}$
${ }^{1,3}$ Departamento de Ingeniería Civil Universidad de Concepción, Concepción, Chile ${ }^{2}$ Section Pavement Engineering, Delft University of Technology,
Delft, Netherlands

Received 5 June 2019; accepted 7 August 2019

\begin{abstract}
Aggregate interlock is the dominant load transfer mechanism in non-dowelled Jointed Plain Concrete Pavements, as the innovative short concrete slabs. Although the Load Transfer Efficiency of this pavement innovation is based on that mechanism, the structural design methods do not relate the Load Transfer Efficiency by aggregate interlock with its direct cause, which is the Crack Width under the joints. The objective of the present article is to characterise in the laboratory the Load Transfer Efficiency-Crack Width relation for innovative short slabs Jointed Plain Concrete Pavements. Additionally, as an alternative to large-scale laboratory tests to study the Load
\end{abstract}

* Corresponding author. E-mail: mpradena@udec.cl

Mauricio PRADENA (ORCID ID 0000-0002-6425-9738)

Lambert HOUBEN (ORCID ID 0000-0002-5594-5357)

Andrés CÉSAR (ORCID ID 0000-0002-0849-2578)

Copyright (C) 2020 The Author(s). Published by RTU Press

This is an Open Access article distributed under the terms of the Creative Commons Attribution License (http://creativecommons.org/licenses/by/4.0/), which permits unrestricted use,

distribution, and reproduction in any medium, provided the original author and source are credited. 
Transfer Efficiency, a practical test on a reduced scale is proposed. The results confirmed that short slabs Jointed Plain Concrete Pavements with high-quality aggregates are able to provide adequate Load Transfer Efficiency (above 70\%) without dowels bars. Based on the laboratory results, complemented with previous field data, a Load Transfer Efficiency-Crack Width curve is proposed and made available for structural design methods of short slabs Jointed Plain Concrete Pavements. Finally, the laboratory test on a reduced scale is useful to develop specific Load Transfer Efficiency-Crack Width relations using standard equipment available in traditional concrete laboratories.

Keywords: aggregate interlock, concrete pavements, crack width, joints, laboratory test, load transfer, pavement design, short slabs.

\section{Introduction}

Aggregate interlock is an effective mechanism in transferring loads across discontinuities, such as joints and cracks, in plain or reinforced cement concrete pavements (Ioannides \& Korovesis, 1990). Actually, in non-doweled Jointed Plain Concrete Pavements (JPCPs), the aggregate interlock, is the most influential load transfer mechanism (Buch, Frabizzio, \& Hiller, 2000; Hanekom, Horak, \& Visser, 2003), being the Crack Width (CW) under the joint the direct cause of its performance (Byrum, Barton, D Rollings, Ioannides, Gemayel, \& Tayabji, 2011; Nowlen, 1968; Walraven, 1980; Wattar, 2002).

A case of non-dowelled JPCPs is the innovation of slabs with optimised geometry (short slabs). The design concept proposes that shortening the slab size allows only one set of wheel loads per slab, and it will reduce the curling stresses. Although the standard design establishes that short slabs are undo welled JPCPs, (Covarrubias, 2012), their performance is equivalent than traditional JPCPs (Roesler, Cervantes, \& Amirkhanian, 2012), but saving up to $25 \%$ of the costs (Covarrubias, 2012; Covarrubias, Pablo, \& Covarrubias, 2008). Certain aspects of the technology of short concrete slabs have been patented (Covarrubias, 2011; Covarrubias \& Pablo, 2012).

In the literature, it is possible to find mechanical methods of structural pavement design where the LTE value is used as an input parameter (Hiller, 2007; Houben, 2006; Söderqvist, 2006; Stet, Leest, \& Frénay, 2006). In these methods, the LTE is defined as a fixed value (or values) determined from indirect causes, i.e. without considering the CW.

Although Salsilli, Wahr, Delgadillo, Huerta, \& Sepúlveda (2015) proposed a mechanistic-empirical design method specific for short slabs, the LTE value of this method is still of the fixed kind (Dirección de Vialidad de Chile, 2012), i.e. without establishing a relationship with the CW, that is its direct cause. Salsilli, Wahr, Delgadillo, Huerta, \& Sepúlveda
Laboratory

Characterization

of the Load

Transfer-Crack

Width Relation

for Innovative Short

Concrete Slabs

Pavements 
(2015) recognise the necessity to make specific studies of LTE in the nondowelled short slabs. In 2018, Pradena \& Houben (2018) studied in the field the LTE-CW relation in short slabs made with Chilean aggregates. In this study, although the LTE values tend to decrease as the CW increases, since $0.7 \mathrm{~mm}$ the LTE maintains an asymptotic behaviour around the $80 \%$ (until $2 \mathrm{~mm}$ ), instead of continuing the LTE reduction. This behaviour contradicts the traditional one, where the LTE decreases with wider cracks and demonstrates the necessity of further studies of the relation LTE-CW.

The asymptotic behaviour was also observed in traditional South African concrete pavements until CW $2.5 \mathrm{~mm}$. Hanekom, Horak, \& Visser (2003) attribute the phenomenon to the use of high-quality aggregates.

The objective of the present article is to characterise in the laboratory the LTE-CW relation for innovative short concrete slabs pavements. Although the characterisation is general, in the present article the laboratory results obtained using the same aggregates, which the Chilean test section of short slabs reported by Pradena \& Houben (2018), are presented to give a better explanation to the singular behaviour observed in the field.

Additionally, as an alternative to the traditional study of the LTE performance through field research or large-scale laboratory tests, a practical test is proposed to develop the LTE-CW relation on a reduced scale. The intention behind this proposal is to define the LTE-CW relation using standard equipment available in traditional concrete laboratories.

\section{Methodology}

\subsection{Practical test method}

Traditionally, the study of load transfer performance has been carried out through field investigations or laboratory tests on large concrete slabs (Brink, Horak, Perrie, Strauss, \& Visser, 2004; Colley \& Humphrey, 1967; Jensen, 2001; Nowlen, 1968). Although these are useful methods, they require special equipment and a considerable amount of resources. Hence, it is necessary to define a practical test method, which allows obtaining the LTE-CW relation simply and optimising resources to facilitate the development of relationships LTE-CW in traditional concrete laboratories of different parts of the world. For this reason, this work was carried out during a research stay at Delft University of Technology (TU Delft), where, based on the detailed study of the aggregate interlock mechanism, simplifications were generated.

The test proposal considers the use of beams of dimensions $100 \times 100 \times 400 \mathrm{~mm}$, where it is possible to study the mechanism 


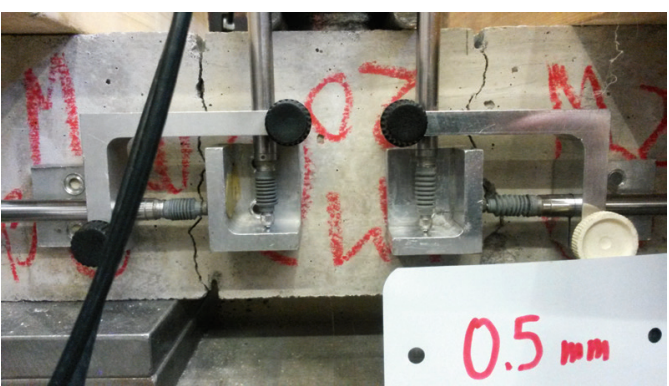

a) cracked sample

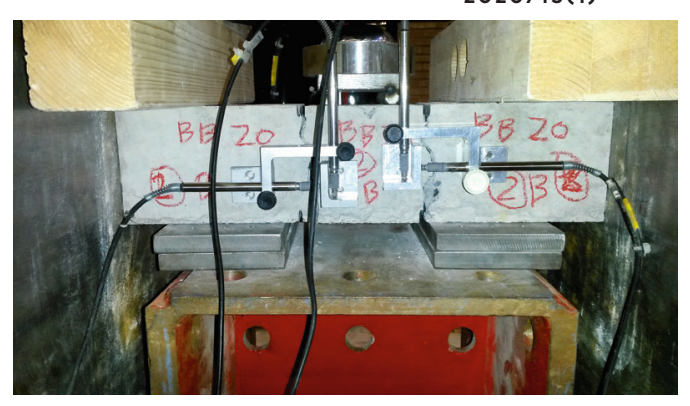

b) test set up

Figure 1. Experimental setup

practically on a reduced scale using aggregates sizes typically applied in pavements. Aggregates with a maximum size of $40 \mathrm{~mm}$ and $20 \mathrm{~mm}$, typically applied in traditional JPCPs and short slabs (Dirección de Vialidad de Chile, 2012, 2018). Furthermore, the present study includes aggregates of $10 \mathrm{~mm}$ maximum size, which are applied, for instance, in two-lift concrete paving (Hu, Fowler, Siddiqui, \& Whitney, 2014).

As the aggregate interlock is a pure shear mechanism (Ramírez, 2010), the beam must be arranged in such a way that only this type of effort is involved in the experiment. It has been chosen to use a test setup based on the one proposed by Thompson (2001) where two cracks are induced in the samples. This setup allows for balancing the horizontal forces without causing undesirable movements during the test (Figure 1a). The process of crack induction is explained in Section 2.2.

The beam is placed in a load frame, and the crack is adjusted to the width of interest. The lateral sections of the beam were supported using wooden blocks on the upper face and positioning steel plates on the side faces. This configuration causes a load differential between both sides of the crack producing double shear stress and a reduction in the risk of rotation (Arnold, Fleming, Austin, \& Robins, 2005). In this way, the symmetrical degradation of both cracks and the configuration of the test allow the study of the effect of shear stresses in the specimen like the in-service conditions of JPCPs (Figure 1).

Using a load frame assembled in TU Delft from an Amsler equipment with a loading capacity of $100 \mathrm{kN}$ and a head diameter of $75 \mathrm{~mm}$, the load was applied statically on the central section of the beam at a rate of $0.02 \mathrm{kN} / \mathrm{s}$ producing a vertical displacement in this section. This displacement was recorded using four Linear Variable Displacement Transducer (LVDT) model Solartron AX/5/S (measurement range $5 \mathrm{~mm}$ and precision $5 \mu \mathrm{m}$ ) placed vertically on both sides of the beam so that 
two measurements per crack were recorded. In addition, to control that no significant change would be produced in the CW, four LVDT devices (model Solartron AX/5/S) were placed horizontally on both sides of the beam (Figure 1b).

\subsection{Cracking the samples and crack width}

Once the beam is demoulded, two vertical saw-cuts of $10 \mathrm{~mm}$ are made, both on the top and bottom sides, at $50 \mathrm{~mm}$ measured from the centre. Afterwards, the beam is placed on the loading machine with the notch just below the actuator. Increasing the load at this critical point causes cracking of the specimen and division of the beam into two segments. The procedure is repeated in the remaining notch, finally obtaining three sections per beam (Figure 2a). The lateral cracked beam sections are adjusted concerning the central section to obtain the CW of interest for the research. In this way, CW of $0.5 \mathrm{~mm}, 1.5 \mathrm{~mm}$ and $2.5 \mathrm{~mm}$ are formed, which cover the spectrum of CW found in JPCPs (Davids \& Mahoney, 1999; Pradena \& Houben, 2015). In the case of short slabs, the CW should be $1.5 \mathrm{~mm}$ as a maximum when the joints are activated, the slabs are effectively shorter than traditional ones, and then the design hypothesis (and benefits) of the short slabs are real (Pradena \& Houben, 2016).

The Crack Width distances are monitored during the test using LVDTs placed horizontally on the beam (Figure 1b), allowing to detect any significant change.

It is important to notice that the provision of LTE by aggregate interlock in JPCPs is based on the irregularities of the cracks faces (Figure $2 \mathrm{~b}$ ). Hence, by the nature of the phenomenon itself, variations of the LTE values are expected, as it occurs between slabs in real-life

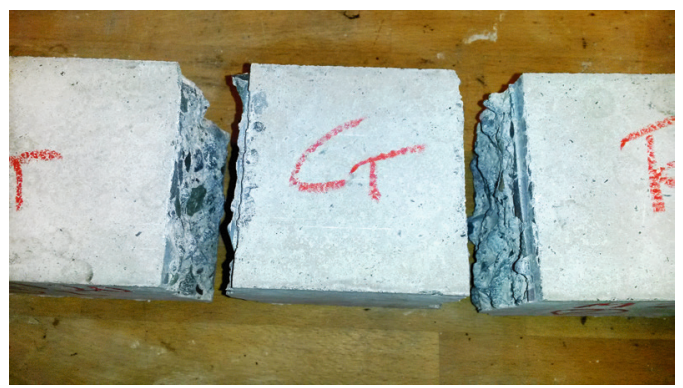

a) top view of the cracked beam

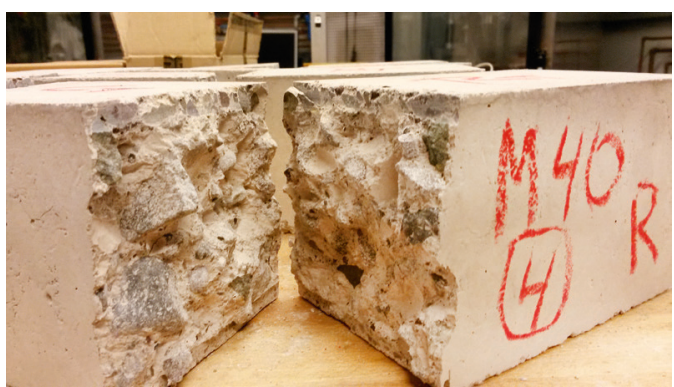

b) irregularities of the crack faces

Figure 2. Cracked specimens 
pavements where the formation of cracks follow a regular or irregular pattern. Hence, certain variability is expected, although the controlled conditions of the laboratory and the fact that the formed cracks travelled almost vertical from the top to the bottom notches (Figure 2). Later, more than exact LTE values, it is important to obtain LTE ranges useful to improve the definition of LTE in structural pavement design methods. The present applied research proposes an improvement relating the LTE by aggregate interlock with its direct cause, which is the CW under the joints.

The present configuration takes advantage of having two cracks per beam, registering the load transfer behaviour in both cracks, which provides more information for the aim of the study.

\subsection{Load type and magnitude}

Previous studies, with high-quality aggregates, have recorded the behaviour of the joints under static and dynamic loads (Brink, Horak, Perrie, Strauss, \& Visser, 2004; Hanekom, Horak, \& Visser, 2003). In South Africa, Brink, Horak, Perrie, Strauss, \& Visser (2004) concluded that static loads present lower LTE values than dynamic loads. In other words, the LTE values obtained from static loads are more conservative than the ones from dynamic loads. Since the Chilean aggregates are also high-quality (Pradena \& Houben, 2018), and the LTE values from static loads are more conservative, at this stage of the development of the LTE-CW relation, it is considered appropriate to opt for a test under static load application.

The load applied during the test must be estimated in such a way that it represents the expected conditions in service. The Concrete Society (2003) assumes that the load transfer occurs up to a distance 0.9 l either side of the load on both sides of the load. Being the radius of relative rigidity expressed as indicated by Eq. (1).

$$
l=\left(\frac{E h^{3}}{12\left(1-v^{2}\right) k}\right)^{0.25},
$$

where $E$ is the Youngs moduli of concrete, $\mathrm{GPa}$; $h$ is the slab weight, m; $u$ corresponds to the Poison ratio, and $k$ is the module of subgrade reaction, $\mathrm{N} / \mathrm{m}^{3}$.

The Eq. (2) allows calculating the stress produced by the passage of a load wheel, which relates the load with the contact area between the faces of the crack. This area is defined as the projected area between the load transfer distance and enough height of the concrete slab $\left(h^{\prime}\right)$, which is the total height of the slab minus the depth of the saw cut.
Laboratory

Characterization

of the Load

Transfer-Crack

Width Relation

for Innovative Short

Concrete Slabs

Pavements 


$$
\tau=\frac{P}{2 l h^{\prime}} .
$$

The pavements are designed considering $80 \mathrm{kN}$ of the standard axle, transmitting each wheel of the vehicle $40 \mathrm{kN}$. However, when the axle weight exceeds $80 \mathrm{kN}$, the value $50 \mathrm{kN}$ was preferred as the standard weight per wheel (Arnold, Fleming, Austin, \& Robins, 2005). Then, for the situation in which a load of $50 \mathrm{kN}$ is applied, a stress value of $250 \mathrm{kPa}$ is obtained.

Eq. (3) determines the load be applied in the test by relating $\tau$ to the width $(x)$ and enough depth $\left(h^{\prime \prime}\right)$ of the beam, which is the total thickness minus the height of the notch to have equivalent results in the reduced scale. As a load of $4 \mathrm{kN}$ provides the equivalent stress of $250 \mathrm{kPa}$, then it is the load applied during the test.

$$
P=2\left(\tau \cdot h^{\prime \prime} \cdot x\right)
$$

\subsection{Determination of Load Transfer Efficiency value}

The concept of differential energy (DE) of the subgrade deformation of the Guide for Mechanistic-Empirical Design of New and Rehabilitated Pavement Structures was applied to use to obtain the Load Transfer Efficiency (LTE) values (National Cooperative Highway..., 2003).

The differential energy is expressed as a function of the reaction module of the subgrade $(k)$, the deflection of the slab under load $\left(w_{L}\right)$ and the deflection of the adjacent slab without load $\left(w_{U}\right)$ as shown in Eq. (4).

$$
\mathrm{DE}=\frac{k}{2}\left(w_{L}+w_{U}\right)\left(w_{L}-w_{U}\right)
$$

On the other hand, the term LTE is defined by relating the deflections between slabs $\left(w_{i}\right)$, as shown in Eq. (5).

$$
\mathrm{LTE}=\frac{w_{U}}{w_{L}} \cdot 100 .
$$

Considering LTE, the Eq. (4) is be rewritten as follows.

$$
\mathrm{DE}=\frac{k}{2}\left(w_{L}+w_{U}\right) \frac{1-\frac{\mathrm{LTE}}{100}}{1+\frac{\mathrm{LTE}}{100}} .
$$

On the other hand, the term $\left(w_{L}-w_{U}\right)$ corresponds to the vertical movement (RM) produced by the differential deflection between the loaded slab and the unloaded slab. 


$$
\mathrm{RM}=\left(w_{L}-w_{U}\right) .
$$

By relating Eq. (7) with the modified term in Eq. (6), the following expression is formed:

$$
\mathrm{LTE}=\frac{100-100 \mathrm{RM}}{1+\mathrm{RM}} .
$$

In this way, it is possible to obtain LTE values at different crack widths from the vertical movement registered by the LVDTs.

\subsection{Aggregates characterization}

Although the aggregates were characterised in TU Delft, they were obtained from samplings of the material used in the test sections of short slabs in Chile used by Pradena \& Houben (2018) to develop their investigation of the relation LTE-CW for short concrete slabs pavements.

Micro Deval (MD), Aggregate Impact Value (AIV) and (ACV) tests were performed to define the quality of the aggregates. The results of these tests were compared to regulations and characteristic values of good quality aggregates. In addition, available data of Los Angeles (LA) abrasion values for the Chilean aggregates were also considered.

The Micro Deval determines the abrasion loss in the presence of water and an abrasive charge. Many aggregates are more susceptible to abrasion when they are wet than dry. The use of water in this test incorporates this effect, and the results are an excellent indicator of field performance (Fowler, Allen, Lange, \& Range, 2006). Low values of MD mean that the aggregates will not suffer significant degradation during service conditions.

The Aggregate Impact Value gives a relative measure of the aggregate resistance to a sudden shock or impact by the BS EN 1097 2:2010 Tests for Mechanical and Physical Properties of Aggregates. Methods for the Determination of Resistance to Fragmentation. The Aggregate Impact Value is expressed as a percentage of the fragmentation of the aggregate caused by the impacts, with low values for strong materials and high values for weak aggregates. On the other hand, the ACV gives a relative measure of the resistance of an aggregate to crushing under a gradually applied compressive load by the BS EN 1097-2:2010.

Finally, the resistance to degradation of coarse aggregate by abrasion and impact in the LA machine has been widely used as an indicator of aggregates quality (Neville, 1995). 


\section{Results and discussions}

\subsection{Quality of the aggregates}

The results of the MD, AIV y ACV tests, together with limit values, are summarised in Table 1 . In the three tests, the results satisfy the requirements demanded by standards, which control the use of aggregates in JPCPs the OPSS.PROV 1002 Material Specification for Aggregates - Concrete for the Micro Deval test and BS EN 12620:2002+A1:2008 Aggregates for Concrete for AIV and ACV.

The first indication of the high quality of the aggregates is given by the AIV result, where a durable aggregate is considered the one with AIV within $10 \%$ to $20 \%$ (Maharjan \& Tamrakar, 2007). Chilean aggregates have only $11 \%$.

The Aggregate Crushed Value value of the Chilean aggregate is only $12 \%$, being $13 \%$ and $14 \%$ the ACV values for basalt and andesite respectively (Harrison \& Bloodworth, 1994), being these rocks recognised by their strong resistance.

According to the characterisation of aggregates made for Chile, the region of origin of the aggregates (Metropolitan Region) presents LA values between $12 \%$ to $14.9 \%$ (Pradena \& Houben, 2018). These LA values are considerably below the $35 \%$ maximum allowed in the specifications of the Chilean Highway Manual (Dirección de Vialidad de Chile, 2018) and the $40 \%$ allowed by the FP-14 Standard Specifications for Construction of Roads and Bridges on Federal Highway Projects. Furthermore, Hanekom, Horak, \& Visser (2003) attribute the asymptotic LTE behaviour to the high-quality of the South African aggregates, which have LA values of $33 \%$ and $21 \%$ (Hanekom, Horak, \& Visser, 2003). Comparing these LA values to the ones of the Chilean aggregates, it is possible to consider the aggregates used in the present research as highquality as well.

Additionally, the aggregate has more than 50\% crushed particles satisfying the minimum requirement for concrete pavements (Dirección de Vialidad de Chile, 2018).

Table 1. Physical properties of aggregates

\begin{tabular}{lcc}
\hline \multicolumn{1}{c}{ Test } & Test result & Specification limit \\
\hline Aggregate Impact Value (AIV) & $11 \%$ & $30 \%$ \\
Aggregate Crushed Value (ACV) & $12 \%$ & $30 \%$ \\
Micro Deval (MD) & $11 \%$ & $14 \%$ \\
\hline
\end{tabular}




\subsection{Laboratory results of the relation Load Transfer Efficiency-Crack Width}

The aggregate interlock mechanism is based on the irregularities on the crack faces (Figure 2). Moreover, the formation of cracks in the field follow a regular or irregular pattern, and then it is possible to find irregularities between the cracks of the in-service pavements. Hereafter, due to the nature of the phenomenon itself, variations between LTE values for a specific CW are possible to find. Although, the controlled conditions of the laboratory and the fact that the formed cracks travelled almost vertical from the top to the bottom notches (Figure 1a), there were still variations between LTE measurements due to the nature of the phenomenon under study. Later, more than exact LTE values, it is essential to obtain LTE ranges useful to improve the definition of LTE in structural pavement design methods. This improvement is possible relating the LTE by aggregate interlock with its direct cause, which is the CW under the joints.

Three repetitions were performed per CW and the maximum size of the aggregates. Part of the concrete mixes used for the preparation of the beams was used for compression tests at 90 days, resulting in all cases over $35 \mathrm{MPa}$. Figure 3 presents the results of LTE for beams with aggregates $40 \mathrm{~mm}$ and $20 \mathrm{~mm}$ under a load of $4 \mathrm{kN}$. In both cases, the highest levels of LTE were obtained with CW $0.5 \mathrm{~mm}$, registering values between $93 \%$ and $99 \%$. This fact evidences that in the case of narrow
Laboratory

Characterization

of the Load

Transfer-Crack

Width Relation

for Innovative Short

Concrete Slabs

Pavements

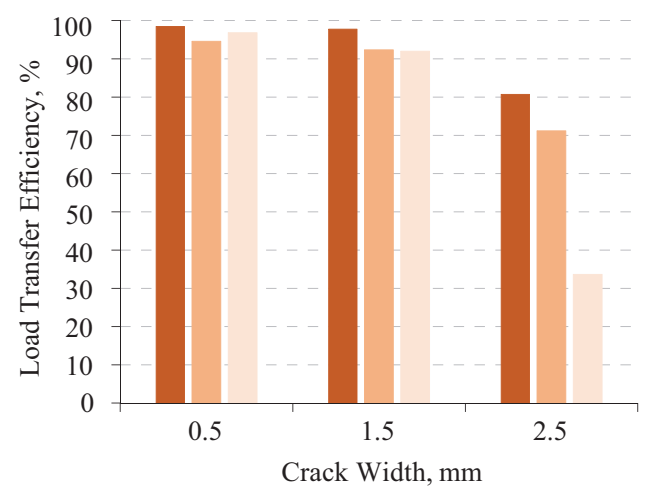

Repetition 1

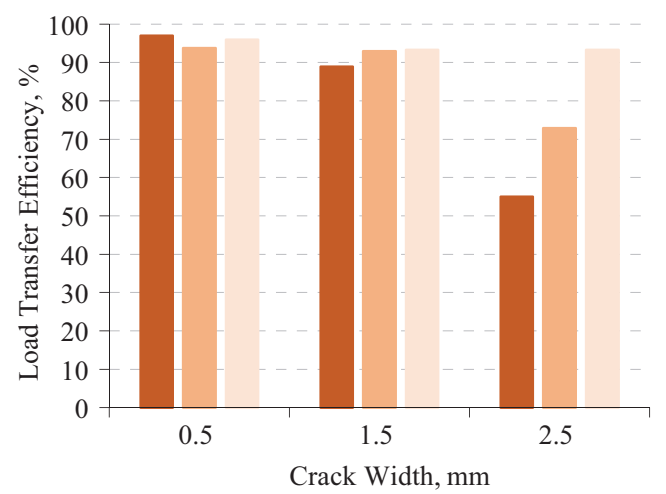

Repetition $2 \quad$ Repetition 3

a) LTE-CW relation for $40 \mathrm{~mm}, 4 \mathrm{kN}$

b) LTE-CW relation for $20 \mathrm{~mm}, 4 \mathrm{kN}$

Figure 3. Load Transfer Efficiency behaviour with Crack Width for aggregates $40 \mathrm{~mm}$ and $20 \mathrm{~mm}$ 
cracks, the influence of the aggregate is neglectable. However, as the crack increases, the behaviour starts to be different for beams of $20 \mathrm{~mm}$ and $40 \mathrm{~mm}$.

With Crack Width $1.5 \mathrm{~mm}$, the LTE value of the $40 \mathrm{~mm}$ beams ranges between $92 \%$ to $97 \%$ and in the case of $20 \mathrm{~mm}$ beams the range of LTE values varying between $88 \%$ and $93 \%$.

In the case of CW $2.5 \mathrm{~mm}$, a fluctuating behaviour is observed for $40 \mathrm{~mm}$ and $20 \mathrm{~mm}$. This behaviour is possible to explain when the role of the base is considered. In effect, the base starts to play a significant role in the provision of LTE by aggregate interlock only since CW $2.5 \mathrm{~mm}$ (Hanekom, Horak, \& Visser, 2003; Jensen, 2001). More specifically, this role is the provision of stability to the system. The less stable behaviour of the samples for CW $2.5 \mathrm{~mm}$, due to the separation of the cracked faces, was possible to observe in the laboratory.

The practical test applied in the present investigation does not consider the base support because it concentrates in the most critical mechanism of load transfer in non-dowelled JPCPs, which is the aggregate interlock (Buch, Frabizzio, \& Hiller, 2000; Hanekom, Horak, $\&$ Visser, 2003). Because that for short concrete slabs, the CW should be $1.5 \mathrm{~mm}$ as a maximum when the joints are activated (Pradena \& Houben, 2016). As the design hypothesis (and the benefits) of this pavement innovation strongly depends that the slabs are effectively short, then the joints must be activated. Otherwise, neither the new traffic load distribution nor the slab curvature reduction is produced.

Figure 3 is possible to observe that without the base support, instability is produced at CW $2.5 \mathrm{~mm}$. In fact, for the case $40 \mathrm{~mm}$, the standard deviation is $1.6 \%$ and $3.2 \%$ for CW $0.5 \mathrm{~mm}$ and $1.5 \mathrm{~mm}$,

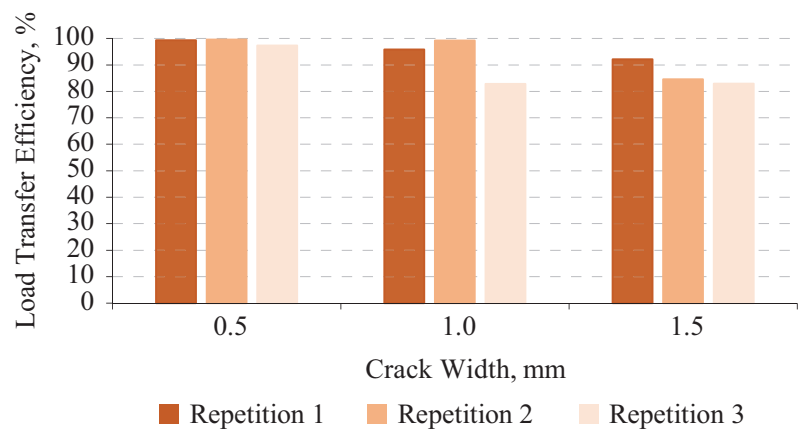

Note: Load Transfer Efficiency-Crack Width, 10 mm, 4 kN.

Figure 4. Load Transfer Efficiency behaviour with Crack Width for aggregates $10 \mathrm{~mm}$ 
respectively. However, at CW $2.5 \mathrm{~mm}$, the dispersion increases and the standard deviation reaches a value of $24.9 \%$.

However, considering the objective of the present research, it is important to highlight that, for the particular case of short slabs, with the majority of their joints cracked, the LTE results are valid within the range where the LTE is provided by aggregate interlock, i.e. up to a crack width of $1.5 \mathrm{~mm}$.

Figure 4 shows the LTE behaviour with CW for aggregates with a maximum size of $10 \mathrm{~mm}$. For these aggregates, the LTE was evaluated only until CW $1.5 \mathrm{~mm}$, due to the lack of aggregates interaction for wider cracks.

\subsection{Proposal of curve Load Transfer Efficiency-Crack Width for the structural design of short slabs Jointed Plain Concrete Pavements}

\subsubsection{Basis of the proposal}

Although the provision of LTE in short slabs JPCPs is based on the aggregate interlock, the pavement design methods do not include a direct relation of the LTE with the crack width under the joints. As a contribution of the present applied research, a first proposal of the LTE-CW curve is made based mainly on the laboratory results with static loads, i.e. more conservative than LTE with dynamic loads. Preliminary cyclic tests until 5 million load repetitions were performed, resulting in equal or greater LTE when compared to the static case, which coincides with the findings of Brink, Horak, Perrie, Strauss, \& Visser (2004). In addition, the proposed curve is limited to the range of typical CW of short slabs (no more than $1.5 \mathrm{~mm}$ ) and aggregates of similar or higher quality properties than the ones used in the laboratory tests.

\subsubsection{Safety factor}

As it has been explained before the provision of adequate LTE by aggregate interlock is based on the irregularities of the crack faces. Even more, especially in real-life pavements, the formation of cracks follows a regular or irregular pattern. As by the nature of the phenomenon itself, variations of the LTE values are expected, more than exact LTE values. It is essential to define LTE ranges useful to relate, in structural pavement design methods, the LTE with the direct cause of it, i.e. the CW.

Figure 5 shows the LTE-CW relation for the short slabs field test made in Chile (Pradena \& Houben, 2018), the laboratory results and the modelling with the software of finite elements for concrete pavements 
EverFE. All cases correspond to the same aggregate and maximum size of $40 \mathrm{~mm}$.

In the field data, there are two zones with different behaviours. In the first zone, between $0 \mathrm{~mm}$ and $0.7 \mathrm{~mm}$, the LTE values decrease as the $\mathrm{CW}$ increases. At the second zone, after $0.7 \mathrm{~mm}$, the LTE values present an asymptotic behaviour are approximately equal to $80 \%$. In the case of the laboratory results, LTE is always above $90 \%$. Hence, it is obvious that the LTE of short slabs with high-quality aggregates are above $70 \%$, which is accepted as a good LTE value for the in-service life of concrete pavements (Bordelon, Roesler, \& Hiller, 2009; Wadkar, Mehta, Cleary, Guo, Musumeci, Zapata, \& Kettleson, 2011). Therefore, effectively, dowels bars are unnecessary. However, considering the differences between the laboratory and field results, it is necessary to establish a criterion, which considers the differences between the controlled conditions of the laboratory and the field conditions. For the proposal of a safety factor, the modelling with EverFE has also been included. Although the model shows initially stable LTE values, after CW $0.3 \mathrm{~mm}$, a continuous reduction of the LTE value occurs. The traditional software is unable to represent the effect of the high-quality aggregates completely, especially for wider cracks, as also has been reported by Hanekom, Horak, \& Visser (2003).

For this purpose, the laboratory LTE-CW curve for $40 \mathrm{~mm}$ was made. In the elaboration of this curve, it is considered that the load transfer is almost complete (LTE is approximately equal to 100\%) when the CW is close to zero.

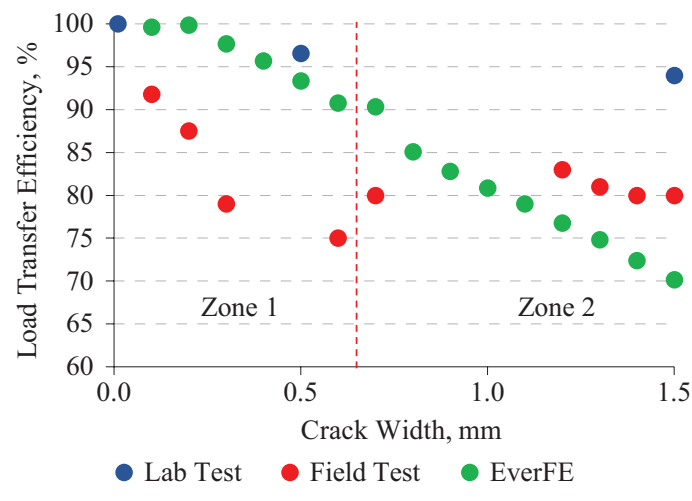

Note: Load Transfer Efficiency-Crack Width, $40 \mathrm{~mm}$.

Figure 5. Relations Load Transfer Efficiency-Crack Width obtained from the field, laboratory tests and modelling with software EverFE 
The values of this curve are grouped into two zones according to the division defined for the field data. For zone 1, the relations between the mean of EverFE and field ( $\mathrm{LTE}_{m}$ ) and laboratory ( $\mathrm{LTE}_{L a b}$ ) data for widths of $0.1 \mathrm{~mm}$ to $0.7 \mathrm{~mm}$ was calculated. The safety factor (SF) was determined as the average of the sum of these relations, which is 0.95 (Eq. (9)).

$$
S F_{i}=\frac{\sum \frac{\mathrm{LTE}_{m}}{\mathrm{LTE}_{L a b}}}{n} .
$$

For zone 2, the process was repeated for widths from $0.8 \mathrm{~mm}$ to $1.5 \mathrm{~mm}$. The safety factor for this case is 0.84 .

\subsubsection{Curve Load Transfer Efficiency-Crack Width for the structural design of short slabs Jointed Plain Concrete Pavements with high-quality aggregates}

Figure 6 presents the design curve developed with the adjusted laboratory values for the case of aggregates $40 \mathrm{~mm}$. The mathematical representation of this design curve is expressed by Eq. (10).

$$
\mathrm{LTE}=-3.856 \ln (\mathrm{CW})+82.135 \text {. }
$$

The proposed curve LTE-CW is valid when aggregates with similar or higher qualities of those presented in this paper are used in the short concrete slabs. However, considering the cost savings in dowels bars, it is important to encourage the construction of short slabs pavements with high-quality aggregates. The excellent provision of LTE given by

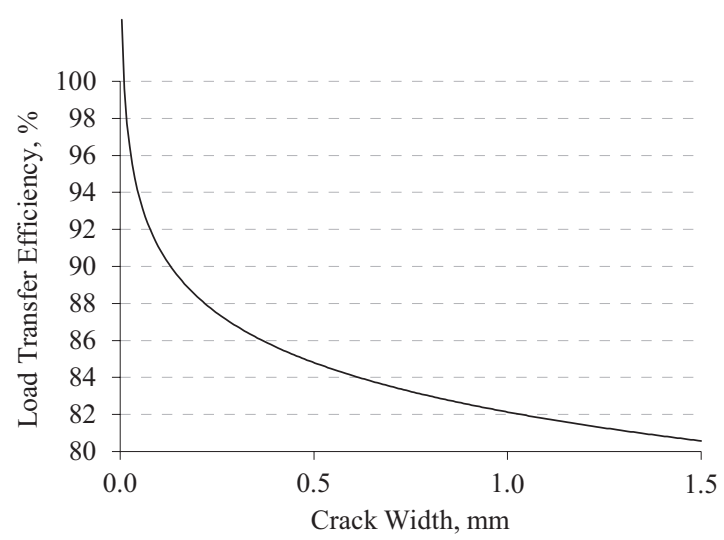

Note: Load Transfer Efficiency-Crack Width, $40 \mathrm{~mm}$.

Figure 6. Design curve of Load Transfer Efficiency-Crack Width for aggregate $40 \mathrm{~mm}$
Laboratory

Characterization

of the Load

Transfer-Crack

Width Relation

for Innovative Short

Concrete Slabs

Pavements 
high-quality aggregates is possible to explain by the irregular surface texture of the cracks faces, as the crack tends to propagate around the particles of the hard aggregates instead of through it (Davids \& Mahoney, 1999; Vandenbossche, 1999).

\section{Conclusions}

1. The Load Transfer Efficiency by aggregate interlock has been being related in the laboratory with its direct cause, which is the Crack Width, particularly for the case of innovative short concrete slabs pavements, which is a non-dowelled Jointed Plain Concrete Pavements. Relating the Load Transfer Efficiency with the Crack Width allows a better definition of the Load Transfer Efficiency for purposes of short slabs structural design.

2. The laboratory work and the comparison of the results to the field measurements confirm that Load Transfer Efficiency by aggregate interlock in Jointed Plain Concrete Pavements is based on the irregularities of the cracked faces. Hence, by the nature of the phenomenon itself, more than exact values of Load Transfer Efficiency is possible to obtain ranges of the relation Load Transfer Efficiency-Crack Width useful for purposes of the structural design of Jointed Plain Concrete Pavements. In effect, these ranges are practical and improve the definitions of Load Transfer Efficiency, which are based, in the best scenarios, on indirect factors.

3. The laboratory results confirmed the trends observed in the field regarding the provision of Load Transfer Efficiency by aggregate interlock in the test section of short slabs Jointed Plain Concrete Pavements used in the comparison. In effect, the adequate provision of Load Transfer Efficiency (above 70\%) of the test section was confirmed. Furthermore, $t$ the asymptotic behaviour observed in the field, and attributed to the use of high-quality aggregates, was confirmed as well. It is essential to notice that the same aggregates of the test section were applied in the laboratory experiments.

4. The obtained results confirm that for short slabs Jointed Plain Concrete Pavements and dowels bars are unnecessary for adequate provision of Load Transfer Efficiency. However, that is related to the fulfilment of the design hypothesis, i.e. slabs must be effectively short, which is directly related to the activation of the joints. In addition, hard aggregates contribute to obtaining the required levels of Load Transfer Efficiency for an adequate 
performance (above 70\%). Hence, it is recommended to provide this kind of aggregates to assure the adequate Load Transfer Efficiency of the non-dowelled short slabs Jointed Plain Concrete Pavements in-service. The curves of Load Transfer EfficiencyCrack Width proposed in the present article are based on highquality aggregates.

5. The development of a test on a reduced scale allows the practical determination of relations Load Transfer Efficiency-Crack Width for short slabs Jointed Plain Concrete Pavements. Avoiding the need to have large work equipment, space, and resources. The test a reduced scale is useful to develop Load Transfer EfficiencyCrack Width relations in typical concrete laboratories of different regions, contributing to the engineering decision making in the structural design of pavements, particularly of innovative short slabs Jointed Plain Concrete Pavements.

6. Previous investigations state that the base of the pavement slab starts to play a significant role in the provision of Load Transfer Efficiency by aggregate interlock only since Crack Width $2.5 \mathrm{~mm}$, providing stability to the system. The test a reduced scale applied in the present investigation confirms this statement. In effect, some instability was observed at the experiments of Load Transfer Efficiency corresponding to Crack Width $2.5 \mathrm{~mm}$.

\section{Acknowledgements}

This work was supported by CONICYT, Program of International Cooperation, under grant REDES 170111. Furthermore, the following organisations are acknowledged: National Highway Laboratory of Chile, and the Chilean Institute of Cement and Concrete.

\section{REFERENCES}

Arnold, S., Fleming, P., Austin, S., \& Robins, P. (2005). A test method and deterioration model for joints and cracks in concrete slabs. Cement and Concrete Research, 35(12), 2371-2383.

https://doi.org/10.1016/j.cemconres.2005.08.002

Bordelon, A. C., Roesler, J., \& Hiller, J. E. (2009). Mechanistic-empirical design concepts for jointed plain concrete pavements in Illinois. Illinois Center for Transportation (ICT).

Brink, A. C., Horak, E., Strauss, P. J., Perry, B. D., \& Visser, A. T. (2004). Improvement of aggregate interlock equation used in CNCPAVE. SATC 2004.
Laboratory

Characterization

of the Load

Transfer-Crack

Width Relation

for Innovative Short

Concrete Slabs

Pavements 
BS EN 1097-2:2010 Tests for Mechanical and Physical Properties of Aggregates. Methods for the Determination of Resistance to Fragmentation

BS EN 12620:2002+A1:2008 Aggregates for Concrete

Buch, N., Frabizzio, M. A., \& Hiller, J. E. (2000). Impact of coarse aggregates on transverse crack performance in jointed concrete pavements. ACI Materials Journal, 97(3).

Byrum, C. R., Barton, P. J., D Rollings, R. S., Ioannides, A. M., Gemayel, C. A., \& Tayabji, S. (2011). Joint Load Transfer in Concrete Airfield Pavements: Final Report. Innovative Pavement Research Foundation Report IPRF-01-G-002-05-2. Rosemont, IL.

Colley, B. E., \& Humphrey, H. A. (1967). Aggregate interlock at joints in concrete pavements. Illinois: Portland Cement Association.

Concrete Society (2003). Concrete Industrial Ground Floors - a Guide to Design and Construction. Technical Report No. 34, 3rd ed, Crowthome, UK.

Covarrubias, J. P. (2012). Design of concrete slabs with optimized geometry and built-in curling effect on performance. In 10th International Conference on Concrete Pavements International Society for Concrete Pavements Holcim (Canada) Transports Quebec.

Covarrubias, T., Pablo, J., \& Covarrubias, J. P. (2008). “TCP Design” for Thin Concrete Pavement. In 9th International Conference on Concrete Pavements International Society for Concrete Pavements Federal Highway Administration American Concrete Pavement Association.

Covarrubias, V., \& Pablo, J. (2012). Design of concrete pavement with optimized slab geometry. Revista Ingeniería de Construcción 27(3), 181-197.

Davids, W. G., \& Mahoney, J. P. (1999). Experimental verification of rigid pavement joint load transfer modeling with EverFE. Transportation Research Record, 1684(1), 81-89. https://doi.org/10.3141/1684-10

Dirección de Vialidad de Chile (2012). Difusión Nuevas Tecnologías y Especificaciones Técnicas Manual Anexo $N^{\circ} 1$ : Método de Diseño de Pavimento de Hormigón con Losas de Espesor Optimizado. Ministerio de Obras Públicas, Santiago, Chile. (in Spanish)

Dirección de Vialidad de Chile. (2018). Manual de Carreteras. Ministerio de Obras Públicas, Santiago, Chile. (in Spanish)

Fowler, D. W., Allen, J. J., Lange, A., \& Range, P. H. (2006). The prediction of coarse aggregate performance by micro-deval and other aggregate tests (No. ICAR 507-1F).

FP-14 Standard Specifications for Construction of Roads and Bridges on Federal Highway Projects

Hanekom, A. C., Horak, E., \& Visser, A. T. (2003, July). Comparison of South African and American aggregate interlock efficiency at concrete pavement joints. In 16th ASCE Engineering Mechanics Conference, Seattle, USA.

Harrison, D. J., \& Bloodworth, A. J. (1994). Industrial minerals laboratory manual: construction materials; a report prepared for the Overseas Development Administration under the ODA-BGS Technology Development and Research Programme. Project 91-1. British Geological Survey. 
Hiller, J. E. (2007). Development of mechanistic-empirical principles for jointed plain concrete pavement fatigue design (Doctoral dissertation, the University of Illinois at Urbana-Champaign)

Houben, L. J. M. (2006). Structural Design of Pavements. Part IV: Design of Concrete Pavements. Lecture notes CT4860. The Delft University of Technology. The Netherlands.

Hu, J., Fowler, D., Siddiqui, S., \& Whitney, D. (2014). Feasibility study of two-lift concrete paving: technical report (No. FHWA/TX-14/0-6749-1). Texas Dept of Transportation. Research and Technology Implementation Office.

Innovative Pavement Research Foundation (2011). Joint load transfer in concrete airfield pavements: final report (Report No. IPRF-01-G-002-05-2)

Ioannides, A. M., \& Korovesis, G. T. (1990). Aggregate interlock: a pure-shear load transfer mechanism. Transportation Research Record, (1286).

Jensen, E. A. (2001). Mechanism of load transfer-crack width relation in JPCP: Influence of coarse aggregate properties. In Seventh International Conference on Concrete Pavements. The Use of Concrete in Developing Long-Lasting Pavement Solutions for the 21st Century. International Society for Concrete Pavements (Vol. 2).

Maharjan, S., \& Tamrakar, N. K. (2007). Evaluation of gravel for concrete and road aggregates, Rapti River, Central Nepal Sub-Himalaya. Bulletin of the Department of Geology, 10, 99-106. https://doi.org/10.3126/bdg.v10i0.1425

National Cooperative Highway Research Program (NCHRP) (2004). Guide for mechanistic-empirical design of new and rehabilitated pavement structures. National Cooperative Highway Research Program 1-37 A.

Neville, A. M. (1995). Properties of concrete (Vol. 4). London: Longman.

Nowlen, W. J. (1968). Influence of aggregate properties on effectiveness of interlock joints in concrete pavements.

OPSS.PROV 1002 Material Specification for Aggregates - Concrete

Pradena, M., \& Houben, L. (2016). Sustainable pavements: correction factor for the modelling of crack width at joints of short slabs. International Multidisciplinary Scientific GeoConference: SGEM: Surveying Geology \& Mining Ecology Management, 2, 245-251.

Pradena, M., \& Houben, L. J. M. (2015). Analysis of the stress relaxation in plain concrete pavements. The Baltic Journal of Road and Bridge Engineering, 10(1), 46-53. https://doi.org/10.3846/bjrbe.2015.06

Pradena, M., \& Houben, L. J. M. (2018). Load transfer-crack width relation of non-dowelled jointed plain concrete short slabs. The Baltic Journal of Road and Bridge Engineering, 13(1), 40-45. https://doi.org/10.3846/bjrbe.2018.388

Ramírez, L. C. (2010). Concrete Mixture Properties Affecting the Aggregate Interlock Mechanism of Joints and Cracks for Rigid Pavement Systems (Doctoral dissertation, University of Pittsburgh).

Roesler, J. R., Cervantes, V. G., \& Amirkhanian, A. N. (2012). Accelerated performance testing of concrete pavement with short slabs. International Journal of Pavement Engineering, 13(6), 494-507. https://doi.org/10.1080/10298436.2011.575134 
Salsilli, R., Wahr, C., Delgadillo, R., Huerta, J., \& Sepúlveda, P. (2015). Field performance of concrete pavements with short slabs and design procedure calibrated for Chilean conditions. International Journal of Pavement Engineering, 16(4), 363-379. https://doi.org/10.1080/10298436.2014.943129

Söderqvist, J. (2006). Design of concrete pavements: design criteria for plain and lean concrete (Doctoral dissertation, $\mathrm{KTH}$ ).

Stet, M. J. A., Leest, A., \& Frénay, J. W. (2006, September). Dutch design tool for jointed and continuously reinforced concrete road pavements. In 10 the International Symposium on Concrete Roads, Brussels, Belgium.

Thompson, I. (2001). Use of steel fibres to reinforce cement bound roadbase (Doctoral dissertation, University of Nottingham)

Vandenbossche, J. M. (1999). Estimating potential aggregate interlock load transfer based on measurements of volumetric surface texture of fracture plane. Transportation Research Record, 1673(1), 59-63. https://doi.org/10.3141/1673-08

Wadkar, A., Mehta, Y., Cleary, D., Guo, E., Musumeci, L., Zapata, A., \& Kettleson, W. (2011). Load-transfer efficiencies of rigid airfield pavement joints based on stresses and deflections. Journal of Materials in Civil Engineering, 23(8), 1171-1180. https://doi.org/10.1061/(ASCE)MT.1943-5533.0000288

Walraven, J. C. (1980). Aggregate interlock: a theoretical and experimental analysis (Doctoral dissertation, The Delft University of Technology)

Wattar, S. W. (2002). Aggregate interlock behavior of large crack width concrete joints in PCC airport pavements (Doctoral dissertation, the University of Illinois at Urbana-Champaign) 